\title{
Design and Implementation plan of E-Tourism and Development: Sample Approach in KSA
}

\author{
Prakash Kuppuswamy, Yahya Alqahtani \\ Lecturer, Department of Computer Engineering \& Networks, \\ Jazan University, Jazan, KSA. ${ }^{1 \text { \& }}$
}

\begin{abstract}
In recent decades the tourism sector has grown rapidly to become a pillar of the global economy, political cooperation, social change and far - reaching advances in technology; both in communications and infrastructure. Tourism has closely been connected to progress of Information Communication Technology for over 30 years. With increasing complexity of tourism business models and tasks, there is a clear need of the next generation in tourism sector. Therefore, we proposing here new structure e-tourism which can support flexible automation, integration, computation, storage, and collaboration. In every year, millions of pilgrims visiting our Holy City, But on the part of tourism and development, Saudi Arabia is less than Europe, America and Asia in the sector of tours and travel development. There is no much significance research proposal or article on e-tourism \& development in our Saudi Kingdom. This paper deals with etourism, innovation and designing proposal suitable for Kingdom of Saudi Arabia. Also we discussed about problems and solutions related to the e-tourism sector adoptable by the industry and government organization in Saudi Arabia.
\end{abstract}

Keywords: - E-tourism, Travel Agent, Web portal, Customer, ICT etc.,

\section{INTRODUCTION}

Technology and Tourism are, at present and in the context of the globalization of the world economy, two of the fastest growing sectors. This trend is creating an unprecedented opportunity for the development of enterprises, institutions and tourist destinations, as well as a growing demand for trained professionals in both fields of knowledge. Tourism organizations today face a challenge of incorporating new information and communication technologies in the development of new models of management and marketing to strengthen their competitiveness.

Tourism as an information intensive industry can gain important synergies from the use of the Internet. The tourism sector has been a pioneer in adopting and developing ICT applications and today is rated among the top product or service categories purchased via the Internet in Spain and other countries [1]. The challenge of eTourism consists of combining the "traditional" marketing techniques with the most advanced marketing solutions which new technologies bring, among which the Internet plays a major role.

Travellers need only a limited amount of information at each stage of their journey, but these multiple "info bits" should be self-consistent throughout the different stages of this journey. They currently obtain such information services by alternative ways in mostly a bulky, static -no real time- and generic -non customizedmanner. However, information is becoming the essential component of the travel service, and therefore it is necessary to be provided at the right time, place and format.

Moreover, real time information gains extremely valuable importance due to the stochastic, dynamic changes of the travel schedules of the various transportation modes. It is more than obvious that the transportation system is subject to several operational constraints of capacity, and mainly it is quite vulnerable to the dynamic changes stem from stochastic events introduced into the network(s). This is even more evident in the case of intermodal transportation, which is, by default, subject to the constraints posed by the effective coordination and the connection possibilities of the participating modes. As a matter of fact, the provision of real time information constitutes a value added service (VAS) for the traveller that could more effectively capture and cope with the stochastic elements of the intermodal system.[2]

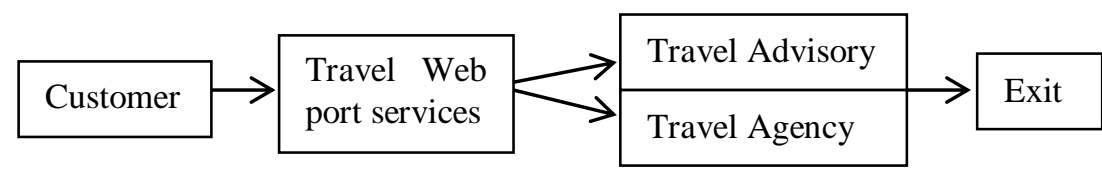

Fig.1 General Structure of e-Tourism 
e-Tourism has created new distribution channels for tourism resulting in the establishment of numerous online booking platforms. These services are increasingly used by customers to purchase tourism products. A survey comparing online booking with booking at traditional travel agents gives insights on the booking behavior of customers [3]. This survey showed that people are using online booking services primarily to book domestic trips, whereas international trips are more often booked with a travel agent. The main advantages of travel agents are their expertise and the face-to-face interaction when making difficult decisions. In contrast, online booking systems are more convenient, have lower response times and provide answers to inquiries in an environment familiar to most users. Note that these results were obtained in Australia and the booking behavior in other countries might be different, due to both sociological as well as geographical reasons.

\section{LITERATURE REVIEW}

Helmut Berger, Michael Dittenbach, Dieter Merkl, Anton Bogdanovych, Simeon Simoff, Carles Sierra(2006) described an e-Tourism environment that takes a community-driven approach to foster a lively society of travelers who exchange travel experiences, recommend tourism destinations or just listen to catch some interesting gossip. This new environment is a perfect re-search playground for examining heterogeneous societies comprising humans and software agents, and their relationship in e-Tourism [3].

M.G. Jaatun, G. Zhao, and C. Rong, (2009) presents in their paper- a promising e-Tourism framework based on emerging semantic grid, in which a number of key design issues are discussed including architecture, ontologies structure, semantic reconciliation, service and resource discovery, role based authorization and intelligent agent. The paper finally provides the implementation of the framework [4].

Teresa Garín-Muñoz, Teodosio Pérez-Amaral (2010) in their study explores the factors influencing Internet usage for travel information and shopping by using representative annual panel data from 2003 to 2007 on the 17 Spanish Autonomous Communities. Our results indicate that the use of Internet for information reasons depends basically on the ICT penetration level in the regions and the demographic characteristics of the population. However, when considering the use of the Internet as a product purchasing tool, variables related to characteristics of travel are also relevant. [1]

Maria Mavri and Vasilis Angelis (2010), discussed about ICT enable travelers to access reliable and accurate information, as well as to make reservations in a fraction of time and the cost. The objective of this work is to measure the impact of ICT on the tourism sector growth. Assuming that the increase of e-tourism sector depends on the increase in tourism demand and internet penetration, we examine the case of all Mediterranean EU member countries, and forecast the growth of online tourism services [5].

Dmitry Zamula (2012) proposes Architecture of a Semantic Framework for E-Tourism Applications The paper describes the requirements of the next generation e-tourism systems. We offer an architecture framework that allows solving new business requirements in this area. We also describe the possible tools for the implementation of this framework [6].

\section{RESEARCH OBJECTIVES}

Tourism, culture and leisure properly combined will become one of the major economic activities of our immediate future. Cultural tourism has to become an excellent meeting point between the tourism and cultural area, and also between the private and public sector. It introduces the advisability of opening up channels of specialization of professionals of the sector aimed at providing knowledge and skills required to face with guarantee the new demands of tourism.

\begin{tabular}{|l|l|l|l|l|l|l|}
\hline Rank & Country & Region & $\begin{array}{l}\text { International } \\
\text { tourist } \\
\text { arrivals } \\
(2012)\end{array}$ & $\begin{array}{l}\text { International } \\
\text { tourist } \\
\text { arrivals } \\
(2011)\end{array}$ & $\begin{array}{l}\text { Change } \\
(2011 \text { to } \\
2012)\end{array}$ & $\begin{array}{l}\text { Change } \\
(2010 \text { to } \\
2011)\end{array}$ \\
\hline 1 & $\mathbf{I}$ France & Europe & 83.0 million & 81.6 million & $+1.8 \%$ & $+5.0 \%$ \\
\hline 2 & E United States & North America & 67.0 million & 62.7 million & $+6.8 \%$ & $+4.9 \%$ \\
\hline 3 & China & Asia & 57.7 million & 57.6 million & $+0.3 \%$ & $+3.4 \%$ \\
\hline 4 & S Spain & Europe & 57.7 million & 56.2 million & $+2.7 \%$ & $+6.6 \%$ \\
\hline
\end{tabular}




\begin{tabular}{|c|c|c|c|c|c|c|}
\hline Rank & Country & Region & $\begin{array}{l}\text { International } \\
\text { tourist } \\
\text { arrivals } \\
(2012)\end{array}$ & $\begin{array}{l}\text { International } \\
\text { tourist } \\
\text { arrivals } \\
(2011)\end{array}$ & $\begin{array}{l}\text { Change } \\
\text { (2011 to } \\
2012)\end{array}$ & $\begin{array}{l}\text { Change } \\
\text { (2010 to } \\
2011)\end{array}$ \\
\hline 5 & Italy & Europe & 46.4 million & 46.1 million & $+0.5 \%$ & $+5.7 \%$ \\
\hline 6 & c. Turkey & Europe & 35.7 million & 34.7 million & $+3.0 \%$ & $+10.5 \%$ \\
\hline 7 & Germany & Europe & 30.4 million & 28.4 million & $+7.3 \%$ & $+5.5 \%$ \\
\hline 8 & United Kingdom & Europe & 29.3 million & 29.3 million & $-0.1 \%$ & $+3.6 \%$ \\
\hline 9 & Russia & Europe & 25.7 million & 22.7 million & $+13.4 \%$ & $+11.9 \%$ \\
\hline 10 & (a) Malaysia & Asia & 25.0 million & 24.7 million & $+1.3 \%$ & $+0.6 \%$ \\
\hline
\end{tabular}

Sources from: World Tourism organization July 2013

Table 1. World top 10 tourist arrival country

Today E-portals has become one of the essentials of corporate success; everyday hundreds of million users come to the Internet looking for services and products from all over the world creating the largest market in humanity. E-portal is converting the Internet to be your best channel for marketing and selling the products and services with low cost and more effect by comparing it to any traditional marketing tools.

Hence, the objective of this research proposal is to engage to construct efficient e-tourism structure suitable for Saudi to share with their religious, culture, environment, knowledge and experience. Here we summarized the objective of the research proposal were as follows:-

- To provide the new business opportunities to the Saudi community to develop their wealth and knowledge.

- To train and inform the public and private tourism sectors in emerging markets.

- To create and raise awareness of the importance of ICT in tourism and development sector.

- Sharing digital data between the global travel trade markets.

- To make connective local business resources such as hotel, transport, accommodation with e-tourism.

- To create network facility with international online mediator and technology providers

- To provide new initiative to expose the culture, history and contribution of the Arabs to the world community.

- To Create awareness, educate and update the travel industry with the latest e-travel strategies

\section{PROPOSED ARCHITECTURE}

The concept of e-tourism architecture that helps service provider to enterprise and travel agent-toagent tourism service. We have started a new service provider business for e-tourism services that is based on two concepts: business process integration and high-grade security in response to variety types of cooperation by the travel agency all over the world. The proposed architecture of this e-tourism service can provide various services such as marketing, Travel arrangement, and Travel advisory, business to hotels, inspection, distribution, payment, and maintenance. It will enable many Travel agencies to construct paper-less office systems easily and also to shorten the response time for quotations with documents.

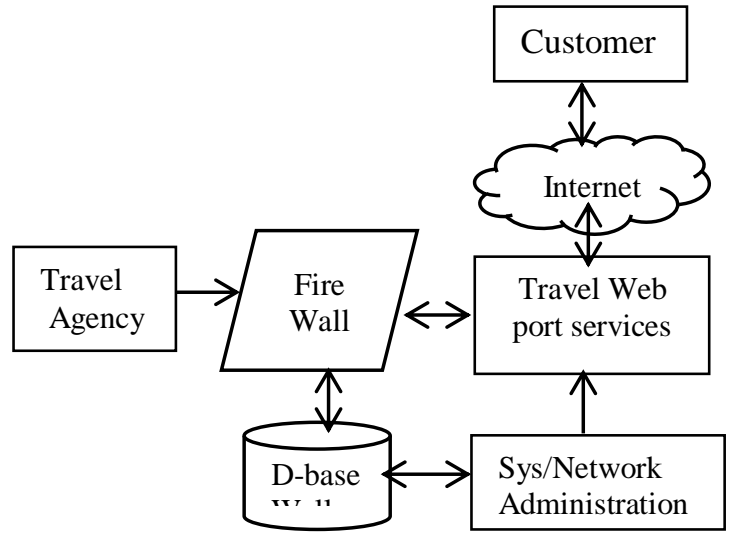

Fig2. Proposed Architecture 


\section{IMPLEMENTATION PLAN}

The technology for infrastructure tool that can enable web applications would require network bandwidth, computer security, and applications to make electronic business a reality. It is important to make sure that a solution is tightly integrated with other systems and operations. The implementation also needs to have the travel agencies and business provider, customer and government support.

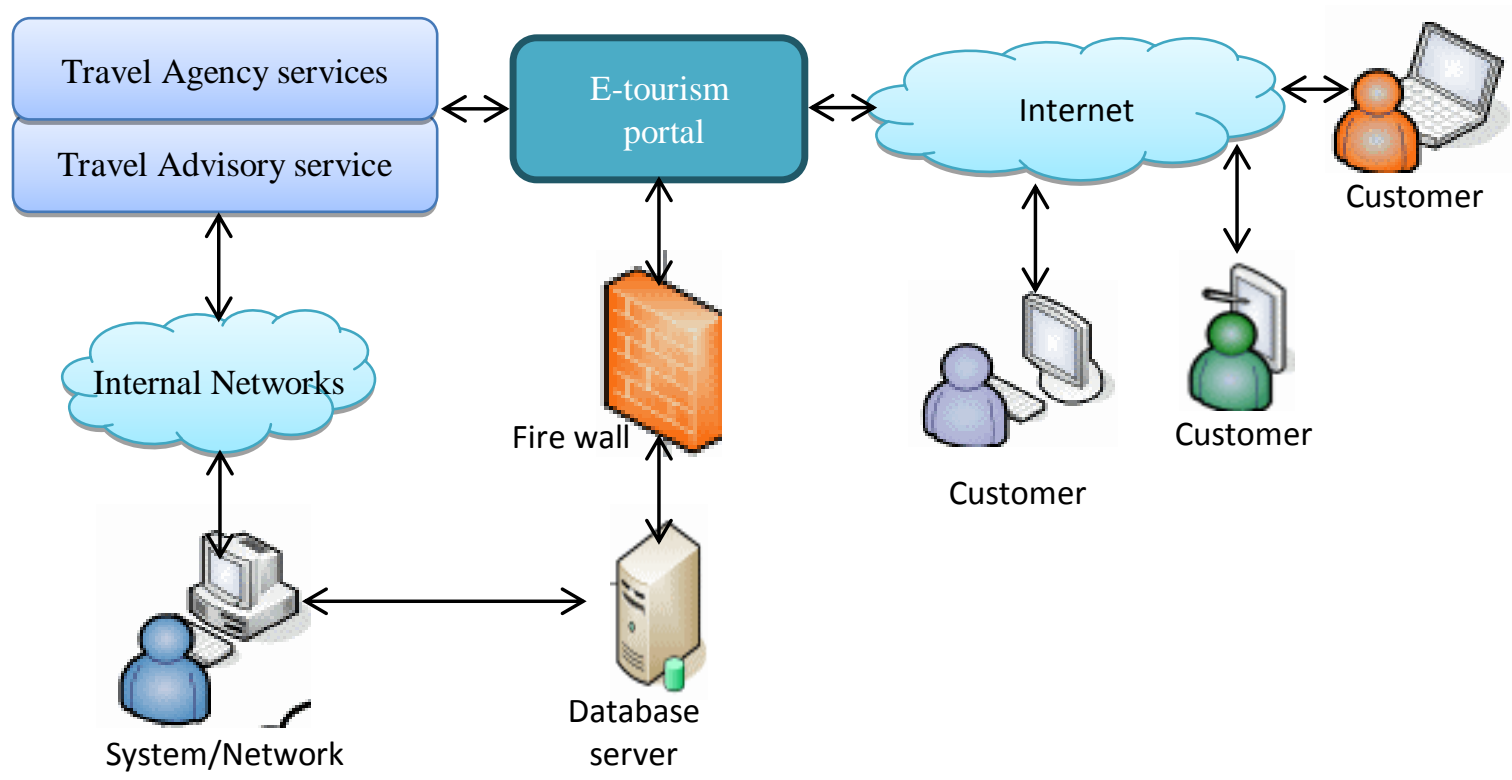

Fig3. Architecture of E-tourism

\section{A. Customer}

Customer Engagement efforts that aim to create, stimulate or influence customer behavior differ from the offline. Customer can use specialization of media such as mobile, smartphone, online form to enquire about e-tourism.

\section{B. Web portals}

Web portal server is an enterprise-level hosting service that serves the most travel agents around the world 24/7 hours. It ensures that reasonable efforts are made to verify the accuracy, consistency, appropriateness, and timeliness of all information placed on the website. Confirm information placed on the cross-agency website is properly reviewed for message consistency and other concerns before it is released. Establish a management plan and regularly reviewing the site. Provide the necessary resources to support website operations, including staffing and training. Automatic backups to ensure e-tourism web portal and its data will always be safe and sound.

\section{Travel Agent}

The role of a Tour Operator is to organize and to provide package holidays. Other roles include: to make contracts with hoteliers, airlines and ground transport, and to print advertising brochures on chosen holidays. A tour operator differs from a travel agent in that a travel agent give advice, sell and administer bookings provided by the tour operator.

\section{System/Network Administrator}

The duties of a system administrator are wide-ranging, and vary widely from one organization to another. System administration are usually charged with installing, supporting, and maintaining servers or other computer systems, and planning for and responding to service outages and other problems. Other duties may include scripting or light programming, project management for systems-related projects. Designing and planning the network setting up the network maintaining the network expanding the network

\section{E. Database Server-}

Customer is reluctant to book the services online, reluctant to disclose the confidential data such as home address, identification number and credit card number and electronic money transaction. The transaction and payment software must perform correct calculations, especially with respect to taxes and other costs. 


\section{F. Security}

Travel agency did not give guarantees on security of information. Customer trust is important such as people recommendation and their experience through transparent legislative infrastructure. Travel service agency need to brand identity of their services. Electronic documents must be customize and should have the same legal validity standard as written signature.

\section{G. Cultural Diversity}

Ability of customization that interface individual and group needs. Customization process is expensive. Translation of language from English into local languages is necessary for better understanding by the customer. Different country has different attitudes towards intellectual property rights, so it is important to ensure to draw the guidelines approach for the intellectual property.

\section{BENEFITS}

In effective e-tourism should enable effective data processing and communication for organizational benefit. E-tourism covers the entire range of electronic tools, which facilitate the operational and strategic management of organization by enabling them to manage their information functions and processes as well as to communicate interactively with their stakeholders for achieving objectives. Also, e-tourism provides the local trade with resources to initiate both e-marketing and e-business. It provides direct support and training for integration of e-tourism solutions at both a public and private sector levels, combining international and local expertise.

Encourage tourists to plan their trips electronically to create channels between and within countries such as the Middle East, Latin America, North African countries, Africa, and the Far East. Finally the benefits directly goes to various type of stakeholders such as Travel \& tourism agents, online tourism agents, advertising media, public relation companies, transportation, Arab and international e-tourism organize, bank, online payment companies, airlines and hotels and government etc.,

The following table and figure shows income earned by the countries in 2012 through tourism and development sector.

\begin{tabular}{|c|c|c|}
\hline Rank & Country & International tourism receipts (2012) \\
\hline 1 & 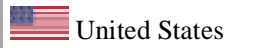 & $\$ 126.2$ billion \\
\hline 2 & Spain & $\$ 55.9$ billion \\
\hline 3 & France & $\$ 53.7$ billion \\
\hline 4 & China & $\$ 50.0$ billion \\
\hline 5 & \& Macau, China & $\$ 43.7$ billion \\
\hline 6 & Italy & $\$ 41.2$ billion \\
\hline 7 & Germany & $\$ 38.1$ billion \\
\hline 8 & United Kingdom & $\$ 36.4$ billion \\
\hline \multicolumn{3}{|c|}{ Sources from: World Tourism organization July 2013} \\
\hline
\end{tabular}

Table 3. Receipt in 2012

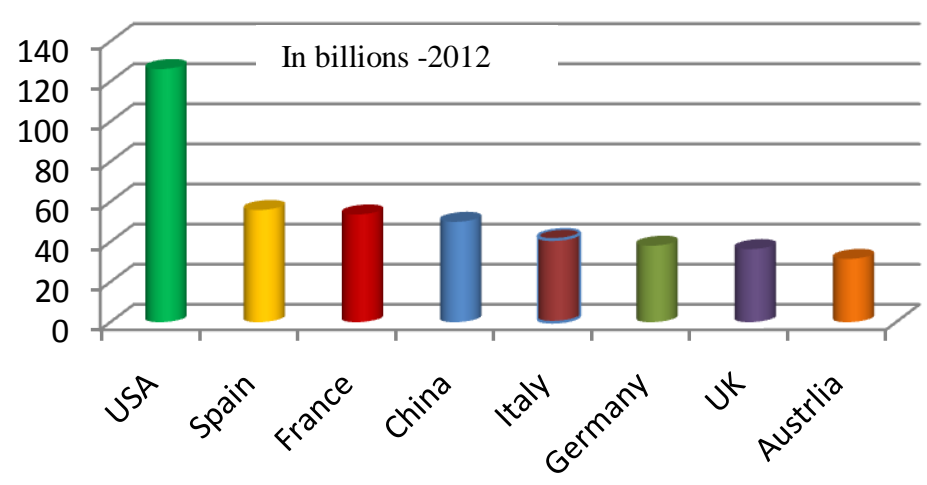

Fig 3. Income by tourist 


\section{CONCLUSIONS}

The proposed structure creates new business opportunities for Saudi Citizen. The development of more specialized services and further consumer integration will lead to economic and cultural diversification. However, current e-tourism applications are dominated by rather conservative approaches in user interface design. Therefore, we argue that appealing visualization of tourism products, the consulting role of travel agents, the social interaction and information exchange between travelers, as well as the information richness of the internet are the key features for successful business in e-tourism. This new environment opens a new gateway for exciting re-search to examine the collaboration in mixed societies comprising both society and agents to study their relationship in e-Tourism.

\section{REFERENCES}

[1] Teresa Garín-Muñoz, Teodosio Pérez-Amaral, "Internet Usage for Travel and Tourism. The Case of Spain”, $21^{\text {st }}$ European Regional ITS Conference, Cophenhagen, 13-15 Sep, 2010.

[2] Konstantinos G. Zografos, Michael A. Madas, "A travel \& tourism information system providing realtime, value-added logistical services on the move", International conference, USA 2002.

[3] Helmut Berger, Michael Dittenbach, Dieter Merkl, Anton, Bogdanovych, ,Simeon Simoff, Carles Sierra, "Opening new dimensions for e-Tourism", 13 November 2006, Springer-Verlag London Limited 2006.

[4] M.G. Jaatun, G. Zhao, and C. Rong, “A Semantic Grid Oriented to E-Tourism”, pp. 485-496, CloudCom, LNCS 5931, , 2009.

[5] Maria Mavri, Vasilis Angelis, "Forecasting the Growth of e-Tourism Sector: The Case Study of Mediterranean Countries", Online at http://mpra.ub.uni-muenchen.de/25439/MPRA Paper No. 25439, posted 25, September 2010.

[6] Dmitry Zamula, "Architecture of a Semantic Framework for E-Tourism Applications", Proceeding of the $12^{\text {th }}$ conference of Fruct Association, ISSN 2305-7254, Oct 2012.

[7] Castronova E, "Virtual worlds: a first-and account of market and society on the cyberian frontier", The Gruter Institute working papers on law, economics, and evolutionary biology, 2001.

[8] Chao Doomasan, "Interface for process management", Proceedings of the Sigchi conference on human factors in computing systems (CHI'01) ACM Press, Seattle, pp152-157, 2001 .

[9] Chittaro L, Coppola P, "Animated products as a navigation aid for ecommerce", In: Extended abstracts on human factors in computing systems (CHI'00) ACM Press, The Hague, Netherlands pp 107-108, 2000.

[10] Gabbard JL, Hix D, Swan JE, "User-centered design and evaluation of virtual environments", IEEE Computer Graph Application 19(6):51-59, 1999.

Prakash Kuppuswamy, Lecturer, Computer Engineering \& Networks Department
in Jazan University, KSA He is research Scholar-Doctorate Degree yet to be
awarded by 'Dravidian University'. He has published 15 International Research
journals/Technical papers and participated in many international conferences in Rep. of
Maldives, Libya and Ethiopia. His research area includes Cryptography, Bio-
informatics and Network algorithms.

